\title{
MEASUREMENT OF MIDSAGITTAL CORPUS CALLOSUM AREA WITH THE MODIFIED CAVALIERI METHOD IN HEALTHY RIGHT- AND LEFT-HANDED TURKISH ADULTS
}

\author{
Mete Ozdikici ${ }^{1}$ \\ Correspondence: meteozdikici@hotmail.com \\ ${ }^{I}$ Department of Radiology, Bakırköy Training and Research Hospital, Istanbul, Turkey.
}

\author{
Article History: \\ Received: March 12, 2019 \\ Accepted: December 20, 2019 \\ Published:January 1, 2020
}

\section{Cite this as:}

Ozdikici M. Measurement of midsagittal corpus callosum area with the modified cavalieri method in healthy right- and left-handed turkish adult. Malang Neurology Journal; 2020.6:24-27.

http://dx.doi.org/10.21776/ub.mnj.202 0.006.01.5

\section{ABSTRACT}

Background: Numerous studies have been published on the anatomy and physiology of the corpus callosum (CC). There are many contradictory studies in the literature about the changes in the size of the CC by handedness, sex, and age.

Objective: This study was carried out to examine the morphometric influence of these factors (handedness, sex, and age) on the CC in healthy Turkish adults

Methods: Two hundred thirty-seven normal individuals, 101 males and 136 females, divided into 5 age groups $(20-29,30-39,40-49,50-59$, and 60-69) were subjected to magnetic resonance imaging (MRI) study of the brain. Of the 237 subjects, 27 males and 36 females were left-handed. Midsagittal corpus callosum area (CCA) was represented by the mean \pm standard deviation of the age groups in square centimeters, and also comparisons of the right- and left-handed were also represented in Table 1. For statistical evaluation, the SPSS 15.0 was used. All statistical tests were set at a $95 \%$ confidence level $(\mathrm{p}<0.05)$.

Results: The range of the reference values (mean values and standard deviation) for the performed measurements in the age groups and for men, women, and total are presented; and comparisons of the right- and left-handed were also represented in Table 1 . In our study, CCA was found $6,46 \pm 1,05 \mathrm{~cm}^{2}$ in all men and $6,17 \pm 0,82 \mathrm{~cm}^{2}$ in all women. The values of CCA are $6,50 \pm 1,05 \mathrm{~cm}^{2}$ in right-handed men and $6,34 \pm 1,03 \mathrm{~cm}^{2}$ in left-handed men, $6,16 \pm 0,80 \mathrm{~cm}^{2}$ in right-handed women, and $6,19 \pm 0,91$ $\mathrm{cm}^{2}$ in left-handed women. There is a statistically significant difference between males and females in CCA $(p<0.05)$. There is no statistically significant difference between the age groups for CCA, and there is no difference between right- and left-handed for men and women ( $>0.05$ ) (Table 2).

Conclusion: The results showed no statistical significance of the effect of age or handedness on the surface area of the CC. However, it was statistically significant that the size of men's CC was higher than that of women.

Keywords: Midsagittal corpus callosum area, modified Cavalieri method, handedness, Turkish adults, magnetic resonance imaging.

\section{Introduction}

The corpus callosum (CC) is a band of white matter that connects the two hemispheres of the brain. It allows information to pass between the right and left hemispheres of the brain. Thus, it is involved in very complex brain functions. Therefore, morphological and morphometric investigations are performed to evaluate the relationship between changes in this structure and neurological findings. Numerous studies have demonstrated the association of morphological abnormalities of the $\mathrm{CC}$ with events such as Alzheimer's disease, cognitive processes, speech dysfunction, dyslexia, mental disorders, seizures, and autism. Some studies correlate variables related to the size and shape of the $\mathrm{CC}$ by age and sex. ${ }^{(1-4)}$

In this study, we aimed to examine handedness, sex, and age differences in midsagittal corpus callosum area (CCA) in healthy Turkish adults.

\section{Methods}

This retrospective study approved by the Ethics Committee was performed on patients who underwent cranial magnetic resonance imaging (MRI) for various reasons and were evaluated as normal. Since the development of the CC was not fully completed, persons under 20 years of age were not included in the study. Before the MRI, the patients were asked whether they used their left hand for eating and writing. On interview and examination, 63 subjects were found to be consistently left-handed: 27 males and 36 females. The study included 237 subjects with ages ranging from 20 to 69 years. The patients were divided into 5 different age groups. Age groups of 20-29, 30-39, 40-49, 50-59, and 60-69, respectively, 58, 53, 41, 35, and 50 healthy individuals were included in this work. 101 of the cases were male and 136 were female. Of the men, 74 were right-handed and 27 were left-handed. 100 of the women are right-handed and 36 of them are left-handed. 
In the course of about 2 years, the cases that we evaluated normally were selected. All image evaluations were performed by a radiologist. Each measurement was performed by a single observer. CC's area measurement was obtained based on MR studies performed in T1 weighted midsagittal MR images (Figure 1a). In the MRI of the sagittal plane, the modified Cavalieri's method was used to determine the normal limits of the midsagittal area of the CC (Figure 1b). CCA was represented by the mean \pm standard deviation of the age groups in square centimeters, and comparisons of the right- and left-handed were also represented in Table 1.

For statistical evaluation, the SPSS 15.0 was used. All statistical tests were set at a 95\% confidence level $(p<0.05)$. CCA was compared between the genders. It was analyzed in relation to age groups. Comparisons of the right- and lefthanded were also investigated. The t-test was used to evaluate the differences between the two independent groups and the one-way ANOVA test was used to determine the difference between the age groups. The results were compared with the literature data.

\section{Results}

The range of the reference values (mean values and standard deviation) for the performed measurements in the age groups and for men, women, and total are presented; and comparisons of the right- and left-handed were also represented in Table 1.
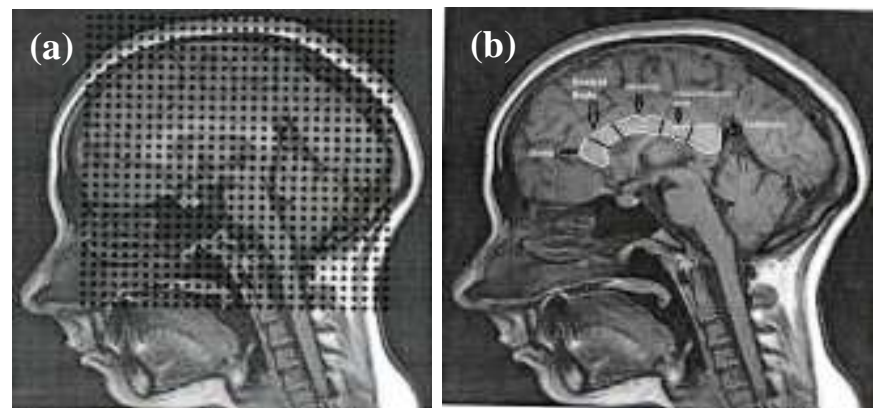

Figure 1. The subdivisions of the corpus callosum in sagittal plane MRI

(a) Estimation of cross-sectional area of corpus callosum in midline plane using the modified Cavalieri method. (b) A transparent square test grid system $(2 \mathrm{~mm})$ was superimposed on corpus callosum

Table 1. Midsagittal corpus callosum area (CCA) was represented by the mean \pm standard deviation of the age groups and sexes in square centimeters. Comparisons of the right- and left-handed were also represented.

\begin{tabular}{|c|c|c|c|c|c|}
\hline Gender & Age group & $\mathbf{N}$ & Handedness & Mean & Std. Deviation \\
\hline \multirow{18}{*}{ Male } & \multirow{3}{*}{$20-29$} & 19 & Right & 6,93 & 1,12 \\
\hline & & 6 & Left & 6,81 & 1,28 \\
\hline & & 25 & Total & 6,90 & 1,13 \\
\hline & \multirow{3}{*}{$30-39$} & 17 & Right & 6,44 & 1,15 \\
\hline & & 6 & Left & 5,75 & 0,94 \\
\hline & & 23 & Total & 6,26 & 1,12 \\
\hline & \multirow{3}{*}{$40-49$} & 11 & Right & 6,50 & 0,76 \\
\hline & & 6 & Left & 6,36 & 1,06 \\
\hline & & 17 & Total & 6,45 & 0,85 \\
\hline & \multirow{3}{*}{$50-59$} & 7 & Right & 6,45 & 0,93 \\
\hline & & 5 & Left & 6,40 & 0,67 \\
\hline & & 12 & Total & 6,43 & 0,79 \\
\hline & \multirow{3}{*}{$60-69$} & 20 & Right & 6,17 & 1,05 \\
\hline & & 4 & Left & 6,41 & 1,16 \\
\hline & & 24 & Total & 6,21 & 1,05 \\
\hline & \multirow{3}{*}{ Total } & 74 & Right & 6,50 & 1,05 \\
\hline & & 27 & Left & 6,34 & 1,03 \\
\hline & & 101 & Total & 6,46 & 1,05 \\
\hline \multirow{18}{*}{ Female } & \multirow{3}{*}{$20-29$} & 20 & Right & 6,08 & 0,73 \\
\hline & & 13 & Left & 5,85 & 0,89 \\
\hline & & 33 & Total & 5,99 & 0,79 \\
\hline & \multirow{3}{*}{$30-39$} & 22 & Right & 6,02 & 0,63 \\
\hline & & 8 & Left & 6,81 & 0,72 \\
\hline & & 30 & Total & 6,23 & 0,73 \\
\hline & \multirow{3}{*}{$40-49$} & 19 & Right & 6,40 & 0,99 \\
\hline & & 5 & Left & 5,90 & 0,99 \\
\hline & & 24 & Total & 6,30 & 0,99 \\
\hline & \multirow{3}{*}{$50-59$} & 20 & Right & 6,14 & 0,72 \\
\hline & & 3 & Left & 6,05 & 0,13 \\
\hline & & 23 & Total & 6,13 & 0,67 \\
\hline & \multirow{3}{*}{$60-69$} & 19 & Right & 6,17 & 0,92 \\
\hline & & 7 & Left & 6,39 & 1,05 \\
\hline & & 26 & Total & 6,23 & 0,94 \\
\hline & \multirow{3}{*}{ Total } & 100 & Right & 6,16 & 0,80 \\
\hline & & 36 & Left & 6,19 & 0,91 \\
\hline & & 136 & Total & 6,17 & 0,82 \\
\hline
\end{tabular}


As can be seen in Table 2 in our study, CCA was found $6,46 \pm 1,05 \mathrm{~cm}^{2}$ in all men and $6,17 \pm 0,82 \mathrm{~cm}^{2}$ in all women. The values of CCA are $6,50 \pm 1,05 \mathrm{~cm}^{2}$ in right-handed men and $6,34 \pm 1,03 \mathrm{~cm}^{2}$ in left-handed men, $6,16 \pm 0,80 \mathrm{~cm}^{2}$ in right-handed women, and $6,19 \pm 0,91 \mathrm{~cm}^{2}$ in left-handed women.

There is a statistically significant difference between males and females in CCA $(\mathrm{p}<0.05)$. There is no statistically significant difference between the age groups for CCA, and there is no difference between right- and left-handed for men and women $(\mathrm{p}>0.05)$.

Table 2. Mean midsagittal corpus callosum area (CCA) was represented in square centimeters.

\begin{tabular}{cccc}
\hline \multicolumn{2}{c}{ Mean midsagittal corpus callosum area $\left(\mathbf{c m}^{2}\right)$} & t-value & p-value* \\
\hline $6,46(\mathrm{n}=101$ males $)$ & $6,17(\mathrm{n}=136$ females $)$ & 2,418 & 0,016 \\
\hline $\begin{array}{c}6,50(\mathrm{n}=74 \text { right- } \\
\text { handed males })\end{array}$ & $\begin{array}{c}6,34(\mathrm{n}=27 \text { left-handed } \\
\text { males })\end{array}$ & 0,697 & 0,488 \\
\hline $\begin{array}{c}6,16(\mathrm{n}=100 \text { right- } \\
\text { handed females })\end{array}$ & $\begin{array}{c}6,19(\mathrm{n}=36 \text { right- } \\
\text { handed females })\end{array}$ & $-0,223$ & 0,824 \\
\hline
\end{tabular}

\section{Discussion}

Our goal in this study was to determine possible changes in the size of the $\mathrm{CC}$ depending on gender, age, and hand preference. It was another goal of our work to be useful in providing the radiologist with parameters that could be helpful in daily practice when evaluating the CC.

The cranial cavity and brain volume are higher in males than females. This volume difference is more pronounced for the cerebellum in particular. In both sexes, the left hemicranium and left ventricle are larger than the right. ${ }^{5}$

In the study of Erdoğan et al., in the subjects with right-eye dominance, the right visual cortex was larger than the left visual cortex, and vice versa in the subjects with left-eye dominance. The right and left cuneal areas were found to be larger in males than in females. ${ }^{6}$ In another study of Erdoğan et al., in right-handers, the volume of the lateral ventricle was higher in the right side than in the left side, but, in lefthanders, it was higher in the left side than in the right side. The volumes of right-lateral and third ventricles were larger in right-handers than in left-handers. There were no sexrelated differences in terms of the volumes of right and leftlateral, third, and fourth ventricles. ${ }^{7}$

Some investigators did not find a significant difference in the midsagittal area of the $\mathrm{CC}$ between schizophrenic patients and normal controls. ${ }^{8}$ In schizophrenic patients, a smaller CC can often be expected, and there are other views. Accordingly, the measurements of $\mathrm{CC}$ size were not different between schizophrenia patients and the control group. CC morphology did not correlate with clinical parameters such as age at onset, duration, or symptom severity. ${ }^{9}$

It is possible to make volume calculations with the Cavalieri method. The formula of the Cavalieri method is given below (10-13): $\mathrm{V}=\Sigma$ Pi.ap.t.

The sum of the points that fell on the object, $\Sigma \mathrm{Pi}$, was then multiplied by the area associated with each point, ap $\left(\mathrm{cm}^{2}\right)$, and the distance between scan slices, $\mathrm{t}(\mathrm{cm})$, to arrive at the volumes of related structures and organs, $\mathrm{V}\left(\mathrm{cm}^{3}, \mathrm{ml}\right)$.

(ap=[SU.d/SL]2; where "SU" is the scale unit of the printed film, "d" is the distance between the test points of the grid, "SL" is the measured length of the scale printed on the film.)
The surface areas of the gaps were measured according to the modified Cavalieri method using a point counting frame. However, by using specially designed test systems, one can obtain an unbiased estimate of the surface area. Since the midsagittal single section of the $\mathrm{CC}$ was used, the $\mathrm{t}$ multiplier value in the standard volume calculation form was not taken. The Cavalieri method has been modified accordingly because only area measurements are made in a single section: $\mathrm{A}=$ Pi.ap.

The CC grows rapidly until the age of 10; It does not change much until the age of 15 ; then grows gradually to reach its maximum size between the ages of 40-50. This development of CC slowly begins to decrease after the age of 50 years. ${ }^{3}$ There is no statistically significant difference between the age groups for CCA in our work.

Some previous works showed greater ${ }^{(14-17)}$ or similar ${ }^{(3,18-22,23)}$ size of the CC in women compared to men. In others, the size of the CC is higher for men than for women, which is statistically significant. ${ }^{24,25}$ Similarly, as in our study, we observed significant sex differences in the CC surface area.

There was a statistically significant difference in the midsagittal area of the CC between right- and left-handed subjects $(p=0.048)^{.25}$ There is no difference between rightand left-handed for men and women in this study.

In one study, the mean area of the $\mathrm{CC}$ was determined as $6,78 \pm 0,88 \mathrm{~cm}^{2}$ in men and $6,37 \pm 0,72 \mathrm{~cm}^{2}$ in women $(p<0.0005) .{ }^{24}$ In our work, these values were found as $6,46 \pm 1,05 \mathrm{~cm}^{2}$ for men and $6,17 \pm 0,82 \mathrm{~cm}^{2}$ for women.

\section{Conclusion}

There is no statistically significant difference between the age groups for CCA, and also there is no difference between right- and left-handed for men and women. Notwithstanding, CCA between men and women may differ in morphometrics. This study may be a resource for the morphometric measurements of the $\mathrm{CC}$.

\section{References}

1. Ridzuan SA, Darussalam SE, Hisham NHM, Namasivayam P, Nichole YMY, et al. A review of burden of caregivers of patients with Alzheimer's disease. Malang Neurology Journal; 2019.5(1):42-45. DOI:10.21776/ub.mnj.2019.005.01.7

2. Oishi M, Mochizuki Y, Shikata E. Corpus callosum atrophy and cerebral blood flow in chronic alcoholics. J Neurol Sci; 1999.162(1):51-55.

3. Guz W, Pazdan D, Stachyra S, Swieton F, Poreba P, et al. Analysis of corpus callosum size depending on age and sex. Folia Morphologica; 2018:1-26. DOI:10.5603/FM.a2018.0061

4. Floris DL, Chura LR, Holt RJ, Suckling J, Bullmore ET, Cohen SB, Spencer MD. Psychological Correlates of Handedness and Corpus Callosum Asymmetry in Autism: The left Hemisphere Dysfunction Theory Revisited. J Autism Dev Disord; 2013.43:1758-72. DOI:10.1007/s10803-012-1720-8

5. Zatz LM, Jernigan TL, Ahumada AJ. Changes on computed cranial tomography with aging: intracranial fluid volume. AJNR Am J Neuroradiol; 1982.3(1):1-11. 
6. Erdoğan AR, Özdikici M, Aydın MD, Aktaş Ö, Dane Ş. Right and left visual cortex areas in healthy subjects with right and left eye dominance. Intern $\mathbf{J}$ Neuroscience; 2002.112:517-23.Jinseung K, Si Eun K. Procalcitonin as a diagnostic and prognostic factor for tuberulous meningitis. J Clin Neurol; 2016.1-8. DOI: 10.3988/jen.2016.12.3.332

7. Erdoğan AR, Dane Ş, Aydın MD, Özdikici M, Diyarbakırlı S. Sex and handedness differences in size of cerebral ventricles of normal subjects. Intern J Neuroscience; 2004.114:67-73.

8. Chua SE, Sharma T, Takei N, Murray RM, Woodruff PW. A magnetic resonance imaging study of corpus callosum size in familial schizophrenic subjects, their relatives, and normal controls. Schizophr Res; 2000.41(3):397-403.

9. Meisenzahl EM, Frodl T, Greiner J, Leinsinger G, Maag $\mathrm{KP}$, et al. Corpus callosum size in schizophrenia-a magnetic resonance imaging analysis. Eur Arch Psychiatry Clin Neurosci; 1999.249(6):305-12.

10. Clatterbuck RE, Sipos EP. The efficient calculation of neurosurgically relevant volumes from computed tomographic scans using Cavalieri's direct estimator. Neurosurgery; 1997.40(2):339-42.

11. Stocchetti N, Croci M, Spagnoli D, Gilardoni F, Resta $\mathrm{F}$, Colombo A. Mass volume measurement in severe head injury: accuracy and feasibility of two pragmatic methods. J Neurol Neurosurg Psychiatry; 2000.68(1):14-17. Towards Matrix. MNJ; 2017.55-60. DOI: 10.21776/ub.mnj.2017.003.02.2

12. Özdikici M. The estimation of lumbar intervertebral disc volumes before and after exercise using the Cavalieri method. MOJ Anat \& Physiol; 2018.5(2):106-08. DOI:10.15406mojap.2018.05.00172

13. Özdikici M. Volumetric evaluation of the paranasal sinuses with the cavalieri method. Anatomy Physiol Biochem Int J; 2018.5(2):1-3. DOI:10.19080/APBIJ.2018.05.555657

14. Driesem NR, Raz N. The influence of sex, age, and handedness on corpus callosum morphology: a metaanalysis. Psychobiology; 1995.23(3):240-47.
15. Jancke L, Staiger JF, Schlaug G, Huang YX, Steinmetz $\mathrm{H}$. The relationship between corpus callosum size and forebrain volume. Cereb Cortex; 1997.7(1):48-56.

16. Johnson SC, Farnworth T, Pinkston JB, Bigler ED, Blatter DD: Corpus callosum surface area across the human adult life span : effect of age and gender. Brain Res Bull; 1994.35(4):373-77.

17. Salat D, Ward A, Kaye JA, Janowsky JS. Sex differences in the corpus callosum with aging. Neurobiol Aging; 1997.18(2):191-97.

18. Allen LS, Richey MF, Chai YM, Gorski RA. Sex differences in the corpus callosum ofthe living human being. J Neurosci; 1991.11(4):933-42.

19. Byne W, Bleier R, Houston L. Variations in human corpus callosum do not predictgender: a study using magnetic resonance imaging. Behav Neurosci; 1988.102(2):222-27.

20. Constant D, Ruther H. Sexual dimorphism in the human corpus callosum? A comparison of methodologies. Brain Res; 1996.727(1-2):99-106.

21. Kertesz A, Polk M, Black SE, Howell J: Sex, handedness, and the morphometry of cerebral asymmetries on magnetic resonance imaging. Brain Res; 1990.530(1):40-48.

22. Weis S, Weber G, Wenger E, Kimbacher M: The controversy about a sexual dimorphism of the human corpus callosum. Int J Neurosci; 1989.47(1-2):169-73.

23. Karim SH, Qasim IG, Akkila SS. A Digital Photogrammetric Study of the Corpus Callosum Using MRI in Sulaimani Normal Individuals. Iraqi J Comm Med; 2012.(3):236-38.

24. Eser O, Haktanır A, Boyacı MG, Doğan FA, Karavelioğlu E. Morphometric Measurement of Corpus Callosum. Türk Nöroşirürji Dergisi; 2011.21(1):14-17.

25. Kocabıyık N, Kılıç C, Baykal B, Tunalı S, Yalçın B, Bulakbaşı N, Ozan H, Akyol M. Morphometric assessment of corpus callosum and cerebral hemispheres with magnetic resonance imaging. Trakya Üniv Tip Fak Derg; 2010.27(4):378-84. 